\title{
REPRIMARIZAÇÃO E DESINDUSTRIALIZAÇÃO: OS IMPACTOS DA LEI KANDIR E DO COMÉRCIO COM A CHINA NO COMPLEXO SOJA
}

\author{
Reprimarization and Deindustrialization: The Impacts of the Kandir Law and of the \\ Trade with China in the Soybean Complex
}

\begin{abstract}
RESUMO
Este artigo objetiva analisar a pauta exportadora do complexo de soja e suas modificações com o advento da Lei Kandir e da participação da China, sob a hipótese de que esses eventos podem gerar externalidades negativas para a economia brasileira em termos de reprimarização da pauta de exportações do país. Para isso, foi realizada uma análise dos dados de produção e comercialização do complexo da soja no Brasil e no mundo, bem como foi realizada pesquisa sobre os fatores que influenciam o comércio desses produtos. Como resultado, observou-se que houve uma queda das exportações de produtos de maior valor agregado, como óleo e farelo e ampliação significativa das exportações de soja in natura. A Lei Kandir, o perfil de comercialização da China e a utilização de práticas de escalada tarifária contribuíram para tal acontecimento.
\end{abstract}

Allan Silveira dos Santos

Universidade de Brasília

allansilveira1@gmail.com

Mateus Boldrine Abrita

Universidade Estadual do Mato Grosso do Sul

mateusabrita@hotmail.com

Érica Oliveira Gonzales

Universidade de Brasília

ericagonzales22@gmail.com

Recebido em: 27/07/2014. Aprovado em: 30/11/2016.

Avaliado pelo sistema double blind review

Avaliador científico: Daniel Carvalho de Rezende

DOI: $10.21714 / 2238-68902016 v 18 n 4 p 289$

\begin{abstract}
This article aims at analyzing the exportation agenda of the soybean complex and its changes with the advent of the Kandir Law and the participation of China, under the hypothesis that these events can generate negative externalities for Brazilian economy in terms of reprimarization of the country's exportation agenda. For this, we analyzed the production and trade data of the soybean complex in Brazil and in the world, and researched the factors that influence the commercialization of these products. As a result, there was a decrease in the exports of products with higher added value, such as oil and bran, and a significant increase in the export of in natura soybean. The Kandir Law, China's trade profile and the use of tariff scale practices contributed for such an occurrence.
\end{abstract}

Palavras-chave: Complexo Soja, Lei Kandir, Exportações e escalada tarifária.

Keywords: Soybean complex, Kandir Law, Exports and tariff scale.

\section{INTRODUÇÃO}

A cadeia de agregação de valor do complexo da soja alterou nos últimos 15 anos. Gradativamente, o Brasil tem aumentado proporcionalmente sua participação no mercado internacional da soja via exportação de bens de baixo valor agregado em detrimento de exportação de bens de maior valor agregado, por exemplo, farelo e óleo de soja.

Esse redirecionamento da pauta exportadora, caso confirmado e levado ao seu extremo pode fazer com que o Brasil elimine importantes elos da cadeia da soja, o que pode levar à ausência de investimentos em novos processos e produtos, perda de empregos de mais alta remuneração e redução do valor adicionado total que pode levar à redução do $\mathrm{PIB}$, ao excesso de dependência dos preços internacionais do farelo, ao aprofundamento dos gargalos de infraestrutura, dentre outros fatores.

Nesse sentido, se há realmente uma reprimarização das exportações e uma das causas é a expansão das exportações agrícolas, é interessante verificar o desenvolvimento das cadeias produtivas. Verificar se até mesmo em setores manufaturados de menor valor agregado, como atividades ligadas ao esmagamento e produção da soja, está havendo um retrocesso.

Nesse cenário, e considerando que a agregação de valor de produtos básicos permite a geração de maior número de empregos, permite a venda de produtos com maior elasticidade-renda da demanda mundial, impulsiona investimentos em pesquisa e 
desenvolvimento e propicia um incremento de valor aos produtos que são exportados, torna-se interessante entender quais os fatores que levam o país a redirecionar as suas exportações para a commodity em seu estado puro, na forma de grãos, em detrimento de sua forma mais bem elaborada e com maior valor agregado, a exemplo do farelo e do óleo de soja.

O presente trabalho tem como hipótese a tese de que tal redirecionamento ocorreu, parte em função da implementação da lei Kandir em 1996, que desonera as exportações de produtos básicos e semielaborados de ICMS, estimulando a exportação de soja em grão em detrimento dos subprodutos farelo e óleo, que têm maior valor adicionado e parte em função da reorientação da pauta de exportações a países como a China, que pratica escalada tarifária, taxando menos o produto de baixo valor agregado e aumentando a tarifação na importação de produtos que tenham valor agregado mais alto.

Caso as hipóteses sejam confirmadas, o objetivo do trabalho é propor um debate sobre as ações que podem ser tomadas para que o país não se torne um mero exportador de soja em grãos em detrimento de produtos mais bem elaborados e com um valor agregado mais alto. Considerando que exportar produtos com alto valor agregado é um objetivo contínuo das economias mais desenvolvidas. Para verificação das hipóteses do estudo, o presente trabalho utilizará como metodologia o estudo dos diversos trabalhos acadêmicos que foram realizados sobre o complexo produtivo da soja, análise de dados de produção e comércio mundial dos principais produtos do complexo de soja, que são o produto sob a forma de grãos, de farelo e sob a forma de óleo. Serão verificados também os dados referentes à comercialização do Brasil com a China, com o intuito de investigar se o advento deste país como principal mercado para a soja brasileira está intimamente ligado com o redirecionamento da pauta exportadora do complexo de soja.

O trabalho, além dessa introdução contará com mais três partes. Inicialmente, será discutida a questão da reprimarização da pauta exportadora brasileira e a importância do avanço da cadeia produtiva em produtos de mais alto valor agregado, discutindo os benefícios advindos disto. No segundo momento, será abordado um panorama sobre a evolução da participação brasileira no mercado mundial de soja ao longo dos últimos anos.

Posteriormente, será realizado um panorama da Produção e Comércio Mundial do Complexo da Soja. Na quinta parte com base nos dados sobre a participação brasileira no comércio mundial, será analisado o efeito da
Lei Kandir e o efeito China sobre a pauta de exportações da cadeia produtiva da soja.

Por fim, são realizadas as considerações finais, com a discussão dos resultados obtidos do trabalho, e as propostas para que o Brasil, na cadeia produtiva da soja, não se torne cada vez mais um exportador de bens de pouco valor agregado em detrimento de atividades que gerem empregos de maior qualidade e maior riqueza para o país.

\section{DISCUSSÃO DA REPRIMARIZAÇÃO DA PAUTA EXPORTADORA BRASILEIRA E A IMPORTÂNCIA DA MANUFATURA PARA GERAÇÃO DE VALOR ADICIONADO.}

O Brasil é um país dotado de diversos recursos naturais, dentre eles a grande quantidade de terras cultiváveis, e é um dos poucos países no mundo que ainda possui terra cultivável. Em função disso, e de aumentos expressivos da produtividade no campo, o Brasil tem expandido sua fronteira agrícola. Além desta expansão, o setor agrícola tem sido o principal produto da pauta de exportação brasileira e um dos setores que tem gerado mais divisas para a economia. Este fato, que por um lado pode ser muito benéfico para o país, por outro também pode revelar uma possível reprimarização da pauta exportadora, com consequências negativas para o país.

A questão da reprimarização da pauta de exportações, desindustrialização e possível ocorrência de doença holandesa preocupam em função das suas consequências para a economia como um todo. Grandes partes das consequências negativas podem estar associadas a uma queda da participação da indústria no valor adicionado na contramão da expansão de setores que possuem menores efeitos de ligação e produção com menor valor adicionado.

Rodrik (2013) cita que o setor de recursos naturais pode ser pensado como um tipo especial de fabricação: um setor que converge muito rapidamente para a fronteira global, que utiliza tecnologia importada, mas tem muito pouca capacidade de absorver o trabalho, porque é altamente capitalizado e intensivo em mão de obra e que, além disso, as suas ligações a montante e a jusante são na maioria dos casos fraca e, portanto, produziriam poucos transbordamentos para o resto da economia.

Rodrik (2013), em seu estudo, identifica que poucos países conseguiram colocar a sua riqueza de recursos para o bom uso no longo prazo. Dentre esses países, o autor citou a Austrália e Nova Zelândia, que são terras de colonização recente e que de acordo com Acemoglu,

Organizações Rurais \& Agroindustriais, Lavras, v. 18, n. 4, p. 289-303, 2016 
Johnson e Robinson (2001) uma das razões para o aproveitamento desse benefício de maneira razoável foi a presença de boas instituições públicas desde o início.

Além desses, Noruega e Holanda também são exemplos de países que colheram ganhos inesperados (a partir de petróleo e gás natural, respectivamente). Porém, nestes dois casos, antes do advento da riqueza de recursos naturais, os países já eram ricos, já tinham desenvolvido instituições sólidas e acumulado altos níveis de capital humano. Desse modo, o autor mostrou que "booms" de recursos naturais tem menor probabilidade de se transformar em uma maldição quando elas acontecem em países que têm boas instituições e níveis elevados de capital humano para começar ou já estão em um estágio relativamente avançado de desenvolvimento (RODRIK, 2013).

Outros argumentos que justificam a preocupação com a reprimarização da pauta exportadora podem ser vistos no trabalho de Oreiro e Feijó, (2010) apud Thirwall, 2002; Tregenna, 2009. Neste trabalho, os autores defendem que deveria haver uma maior preocupação com a reprimarização da pauta exportadora e com a consequente queda do produto industrial no quantum exportado, pois estes últimos possuem a capacidade de gerar as seguintes características e efeitos positivos para a economia:

(i) Os efeitos de encadeamento para frente e para trás na cadeia produtiva são mais fortes na indústria do que nos demais setores da economia.

(ii) A indústria é caracterizada pela presença de economias estáticas e dinâmicas de escala, de tal forma que a produtividade na indústria é uma função crescente da produção industrial.

(iii) A maior parte da mudança tecnológica ocorre na indústria. Além disso, boa parte do progresso tecnológico que ocorre no resto da economia é difundida a partir do setor manufatureiro.

(iv) A elasticidade renda das importações de manufaturas é maior do que a elasticidade renda das importações de commodities e produtos primários. Dessa forma, a "industrialização" é tida como necessária para aliviar a restrição de balanço de pagamentos ao crescimento de longo prazo.

A tese de que a manufatura é importante para a economia também é corroborada por outros autores. Costa e Gonçalves (2011), por exemplo, através de um estudo da matriz insumo produto no Brasil, constatou que, de fato, setores industriais possuem mais efeitos de ligação para frente e para trás na economia, confirmando a importância do setor industrial para o crescimento da economia de um país.

Mantendo essa linha de pensamento, Helper, Krueger e Wial (2012), em estudo realizado para a economia americana, destaca a importância da manufatura, pois ela continua a prover os empregos com salários mais altos, continua sendo a principal fonte de inovação comercial e é essencial para inovação do setor de serviços e essencial para reduzir o défice comercial da nação.

Outros autores como Rodrik (2013), também em um estudo realizado para a economia americana, induzem que a industrialização e as exportações de manufaturados têm sido o alicerce para o crescimento rápido e sustentável.

É em virtude de argumentos como este, que foi apresentado por Rodrik (2013), que autores como Oreiro e Feijó (2010) têm demonstrado a preocupação em investigar se está havendo uma reprimarização da pauta de exportações no Brasil, aliado a um processo de desindustrialização e doença holandesa ${ }^{1}$.

Quanto a esta questão, há de se atentar que a desindustrialização não está necessariamente associada a uma "reprimarização da pauta de exportação". A transferência para o exterior de partes da cadeia produtiva que têm menor importância para a geração de valor agregado ou até mesmo de indústria que é mais intensiva em mão de obra e ou recursos naturais, preservando no país atividades de alto valor agregado, conteúdo tecnológico e que propiciam maior valor adicionado às exportações, é um exemplo de que nem sempre a desindustrialização pode ser acompanhada de uma reprimarização (OREIRO ; FEIJÓ, 2010 apud BRESSER-PEREIRA, 2008).

Para as situações em que não houve reprimarização e que houve a manutenção de atividades que geram alto valor agregado, diz-se que a desindustrialização pode ser encarada como positiva. No entanto, se a desindustrialização vier acompanhada de uma "reprimarização" da pauta de exportações, ou seja, por um processo de reversão da pauta exportadora na direção de commodities, produtos primários ou manufaturas com baixo valor adicionado e ou baixo conteúdo tecnológico isso pode ser sintoma da ocorrência de "doença holandesa", ou seja, a desindustrialização causada pela apreciação da taxa real de câmbio resultante da descoberta de recursos naturais escassos num determinado país ou região (OREIRO; FEIJÓ, 2010 apud BRESSER-PEREIRA, 2008).

${ }^{1}$ De acordo com Bresser-Pereira (2008)A doença Holandesa é caracterizada como uma apreciação crônica da taxa de câmbio resultante da abundância de recursos naturais de determinado país ou região, ao qual inviabilizaria as demais indústrias de bens comercializáveis. 
Em relação ao que se tem observado no Brasil, Carvalho e Carvalho (2011), em seu estudo, revelaram uma mudança da pauta favorável às exportações de produtos primários que sugerem uma reprimarização. A razão para isso está ligada ao aumento da demanda mundial por commodities que elevou os preços dos alimentos e das matérias-primas provenientes de recursos naturais. Tal situação, entretanto, poderá ser revertida quando a taxa de câmbio nominal voltar a ser depreciada e os investimentos em infraestrutura logística e em inovações forem retomados (CARVALHO; CARVALHO, 2011).

Costa e Gonçalves (2011), por exemplo, notaram que houve uma maior especialização na pauta de exportações brasileira baseada em recursos naturais no período pós-abertura comercial e que isto foi resultado da ação conjunta dos seguintes fatores, exportação em maior quantidade de produtos intensivos em recursos naturais e importação de produtos intensivos em tecnologia, que possuem valor agregado mais alto. Para o autor, ficou demonstrada uma visível perda de densidade da indústria, que resultou na perda de elos de cadeias verticais de suprimento, o que trouxe consequências negativas à economia.

Ainda na visão dos autores acima, tal reprimarização pode ter sido resultada da liberalização econômica e expansão do "agronegócio" que resultou no aumento das exportações de matérias-primas agropecuárias de baixo valor agregado, ou seja, nas chamadas commodities agrícolas e minerais (COSTA; GONÇALVES, 2011).

A integração seria positiva, se a pauta de exportações evoluísse nos anos subsequentes à abertura, de forma a configurar estruturas nas quais ganhassem importância relativa os produtos de maior valor agregado, isto é, os manufaturados. No entanto, “...Manteve-se a participação alta, e até crescente, das vendas externas associadas às atividades agrícolas e minerais e, dentre essas, das de relativamente baixo grau de transformação industrial" (Costa e Gonçalves, 2011 apud BENETTI, 2006, p.7).

Silva (2014) analisou se o processo de desindustrialização que o Brasil apresenta é fruto de doença holandesa, e concluiu que a entrada de capitais e a valorização dos preços internacionais das commodities exportadas pelo país resultaram em apreciação do câmbio real. Todavia seus impactos sobre a indústria de transformação indicam que o fenômeno se deu apenas de forma relativa, pois a estrutura produtiva do país não perdeu elos importantes que possam ter causado a reprimarização.
Nassif (2008) buscou investigar se o Brasil passou por processo de desindustrialização pela via "natural", ou seja, aquela que ocorre quando um país está em sua trajetória de desenvolvimento, sendo caracterizada como não prejudicial para o desenvolvimento de longo prazo da nação e seria fruto de um desenrolar inerente ao desenvolvimento, a luz do que ocorreu com outras nações desenvolvidas. $O$ trabalho demonstra que o período de 1990 até 2008 não pode ser enquadrado como de "desindustrialização", pois, mesmo com as baixas taxas de crescimento médias anuais do PIB brasileiro entre 1990 e 2000, a indústria de transformação doméstica conseguiu manter um nível de participação médio anual satisfatório. Todavia o autor já alertava para os riscos, no longo prazo, inerentes à tendência recorrente de sobrevalorização da moeda brasileira, como a perda de competitividade industrial, como principalmente a um processo precoce de desindustrialização.

Nesse sentido, Sonaglio et al. (2010) buscaram analisar evidências de um processo de desindustrialização para a economia brasileira por meio de dados em painel. Os resultados apontam para a existência de queda das exportações de bens de alta tecnologia e aumento de bens não industriais, fato que está muito relacionado à taxa de câmbio apreciada e taxa de juros elevada. Os modelos indicam que as exportações respondem às flutuações cambiais de forma direta, assim, observou-se que no período analisado houve alteração na pauta de exportações, mas o trabalho não possui elementos enfáticos para afirmar que essa mudança tem caráter estrutural e que, portanto, o Brasil esteja passando por um processo de "doença holandesa".

Analisando o período mais recente Carvalho e Kupfer (2011) são mais categóricos na análise da desindustrialização prematura no Brasil. Baseando sua pesquisa no trabalho de Imbs e Wacziarg (2003) sobre a relação entre a especialização da estrutura produtiva e a renda per capita de um grupo de países. Os autores buscaram determinar a trajetória de mudança estrutural percorrida pela indústria brasileira nas últimas décadas, com o propósito de compará-la com o padrão encontrado pelos autores e com as trajetórias de alguns países selecionados e também analisam a especialização no emprego. Assim, a inflexão da trajetória no caso brasileiro ocorreu em um nível de renda menor do que o verificado em todos os outros países da análise comparativa, a uma renda per capita de cerca de US\$ 4.000 (constantes de 1990), enquanto nos demais países, o ponto de inflexão da diversificação para especialização ocorre em torno de 
US\$ 22.000 para os EUA, US\$ 17.000 para o Reino Unido, US\$ 15.000 para o Japão e US\$ 8.000 para a Coreia do Sul. Portanto, o fato de a inflexão da trajetória brasileira ocorrer em níveis de renda per capita muito inferiores aos dos demais países do estudo dá indicativos de que o processo de especialização da indústria brasileira está ocorrendo de forma precoce (prematura) e não fruto de um processo natural do desenvolvimento. Algum fator exógeno pode estar influenciando nessa desindustrialização prematura, como: abertura comercial abrupta dos anos de 1990, liberalização e doença holandesa.

Entretanto, não é consenso que tenha havido uma reprimarização da pauta exportadora. Autores como Nascimento e Cardozo (2009) argumentam que na realidade não houve desindustrialização, mas sim um aprofundamento da dependência estrutural de commodities. Ou seja, apenas houve uma acentuação de um processo que é histórico na economia brasileira.

Entretanto, convém ressaltar, que mesmo não achando tais evidências, o autor revelou preocupação quanto a uma possível redução significativa do peso relativo dos produtos industrializados intensivos em trabalho no total do valor adicionado e das exportações brasileiras.

Ainda segundo o autor, essa perda se torna mais preocupante, pois não houve em concomitância com ela o avanço de setores cuja intensidade tecnológica é mais alta e que poderia transbordar efeitos positivos para os demais setores da economia, como setores intensivos em escala e em conhecimento.

Considerando o exemplo de países que possuíam instituições sólidas e que já eram ricas e que não tiveram problemas significativos com a exploração de recursos naturais e ainda, considerando que nem sempre a desindustrialização é encarada como um fator negativo percebe-se que o problema da reprimarização da pauta exportadora pode estar muito mais associado a fatores de falta de coordenação das políticas macroeconômicas, ausência de políticas capazes de aproveitar e redirecionar os recursos oriundos das commodities do que propriamente a exploração destas commodities.

Nesse contexto, analisar o caso do complexo da soja, no que concerne à produção de valor agregado tornase importante para que possamos identificar possíveis problemas que podem impedir uma escalada na agregação de valor ou que estejam propiciando uma reprimarização dentro da própria cadeia produtiva da soja. Nos próximos tópicos, esta cadeia produtiva será analisada.

\section{PROGRESSO DA PRODUÇÃO BRASILEIRA DE SOJA}

A produção de soja foi iniciada na China, e, a partir do século XX, sua importância econômica vem aumentando devido às diversas possibilidades de aplicação industrial, entre elas a produção de óleo para a indústria de combustível, farmacêutica, de estética, ou até mesmo em forma de grãos para a indústria alimentícia e de farelos, muitas vezes utilizadas nas rações de animais. A soja chegou ao Brasil em 1882, através dos EUA. Entre 1900 e 1901 foram distribuídas as primeiras sementes de soja para os produtores do estado de São Paulo, através do Instituto Agronômico de Campinas (BOIFÁCIO et al., 2013).

Em 1941 houve a primeira referência de produção comercial de soja no Brasil, que obteve uma área cultivada de 640 ha, produzindo 450 toneladas e rendimento de 700 $\mathrm{kg} / \mathrm{ha}$. Em 1949 ocorreu o primeiro registro internacional com a indicação do Brasil como produtor de 25 mil toneladas. Já nos anos 50, a produção de soja no Brasil alcançou 100 mil toneladas e na década seguinte, essa produção conseguiu estabelecer-se no Brasil como uma cultura economicamente importante, passando de 206 mil toneladas, no ano de 1960, para 1,06 milhão de toneladas no ano de 1969. Aproximadamente 98\% desse volume eram produzidos na região Sul do país (AGNOL, LAZAROTTO e HIRAKURI, 2010).

Apesar do significativo crescimento da produção de soja ao longo da década de 1960, foi na década seguinte que o crescimento da soja foi mais expressivo, e, com isso, se consolidou como a principal cultura do agronegócio nacional, passando de 1,5 milhão de toneladas, no ano de 1970, para mais de 15 milhões de toneladas em 1979. No final da década de 70, mais de $80 \%$ da produção de soja ainda estavam concentrados nos três estados da região Sul, embora o Cerrado, na região central do país, sinalizasse que atuaria de forma mais intensiva no processo produtivo da oleaginosa, o que efetivamente ocorreu na década de 80 (AGNOL, LAZAROTTO e HIRAKURI, 2010).

Também na década de 70 , o crescimento médio em produção de soja ao ano foi de $22 \%, 17 \%$ em área e $3,6 \%$ em produtividade. Tal crescimento também pode ser atribuído ao resultado da combinação de preços atrativos do mercado internacional e elevada disponibilidade de crédito com juros subsidiados para a produção nacional. Já na década de 80 , o crescimento foi de $3 \%$ ao ano, tanto na área quanto na produção, ou seja, o crescimento foi pequeno e a produtividade foi praticamente a mesma. A produção dos principais estados produtores (Rio Grande 
do Sul e Paraná) foi muito instável, sobretudo por fatores climáticos (PAULA e FAVERET FILHO, 1998).

A produção de soja alcançou na safra de 1997/1998, 31,3 milhões de toneladas, ocupando uma área de 11,4 milhões de hectares com uma produtividade que alcançava $2.308 \mathrm{~kg} / \mathrm{ha}$. Na década de 1990, o desempenho da produção foi atribuído ao crescimento de produtividade, pois o acréscimo da área foi de 2,1\% ao ano, enquanto a produção apresentou uma taxa de $8,6 \%$ ao ano. Isso ocorreu em decorrência de um aumento de $4,9 \%$ ao ano na produtividade média (PAULA e FAVERET FILHO, 1998).

De acordo com Garcia e Zaparolli (2006), o índice de evolução da produção de soja no Brasil foi crescente entre 2000 e 2005, com uma pequena redução em 2003/2004. A cada ano, a tendência de crescimento da produção se torna mais acentuada em relação ao período anterior.

O resultado dessa expansão contínua é que o Brasil, apesar de ainda não ter se consolidado como principal produtor mundial de soja, já alcança patamares de produção semelhantes aos Estados Unidos, e é bem possível que nos próximos anos até supere a produção americana, conforme pode ser visualizado na Tabela 1 .

\section{PRODUÇÃO E COMÉRCIO MUNDIAL DO COMPLEXO DA SOJA}

De acordo com Brum et al. (2005), entre os anos 1992/1993 e 1998/1999, o mercado internacional da soja evoluiu da seguinte forma: a produção mundial chegou a 156 milhões de toneladas em 1998/1999, após ter obtido o recorde histórico no ano anterior com 158,1 milhões de toneladas. O volume produzido concentrado nos EUA era 74,1 milhões de toneladas, no Brasil era de 30,7 milhões, Argentina 18,8 milhões e na China 13,2 milhões de toneladas.

O esmagamento da soja para a produção de óleo, alcançava um total de 133,4 milhões de toneladas, das quais os EUA participavam com 33,5\% e o Brasil com $15,9 \%$. A Argentina e a China participavam com 12,3 e $8 \%$ respectivamente. O maior importador de grãos de soja era a União Europeia, importando 16 milhões de toneladas, em seguida o Japão, 4,69 milhões de toneladas e a China que importava 3,8 milhões de toneladas.

No mesmo período, a produção de farelo de soja subia a 105,5 milhões de toneladas, concentradas nos EUA, Brasil, Argentina e União Europeia. O Brasil consumia apenas 5,9 milhões de toneladas. O maior importador de farelo de soja também foi a União Europeia, com 17,2 milhões de toneladas, que representam $47 \%$ do comércio mundial do produto. Já a produção do óleo de soja se manteve estacionada em torno de 24 milhões de toneladas, sendo os EUA o maior produtor com 8,4 milhões de toneladas, o Brasil produzia 4 milhões de toneladas e a Argentina 2,9 milhões (BRUM et al., 2005).

$\mathrm{O}$ valor das importações mundiais era de apenas 7,6 milhões de toneladas, com o maior importador sendo a China, importando 1 milhão de toneladas de óleo de soja. O óleo de palma assumiu a liderança de produção e consumo mundial, com 18,8 e 12,3 milhões de toneladas produzidos no ano inteiro (BRUM et al., 2005).

Quanto aos estoques do produto e perspectivas de preço no período mais recente, temos que em 2010 ocorreu o aumento da produção mundial da soja ${ }^{2}$. Esse aumento

Vide Tabela 1.

TABELA 1 - Produção de soja no mundo (milhões de toneladas)

\begin{tabular}{|c|c|c|c|c|c|}
\hline País/Safra & $2009 / 10$ & $2010 / 11$ & $2011 / 12$ & $2012 / 13$ & $2013 / 14^{*}$ \\
\hline Brasil & 69,00 & 75,30 & 66,50 & 82,00 & 85,00 \\
\hline Estados Unidos & 91,42 & 90,61 & 84,19 & 82,06 & 88,60 \\
\hline Argentina & 54,50 & 49,00 & 40,10 & 49,50 & 53,50 \\
\hline China & 14,98 & 15,10 & 14,48 & 12,80 & 12,50 \\
\hline Índia & 9,70 & 9,80 & 11.00 & 11,50 & 12,30 \\
\hline Paraguai & 6,46 & 7,13 & 4,04 & 9,37 & 8,40 \\
\hline Canadá & 3,58 & 4,45 & 4,30 & 4,93 & 5,30 \\
\hline Outros & 10,76 & 12,55 & 14,54 & 15,43 & 16,12 \\
\hline Total & 260,40 & 263,94 & 239,15 & 267,59 & 281,72 \\
\hline
\end{tabular}

Fonte: Usda - Agosto de 2013, adaptado CONAB - Conjunturas Prospecção - 2013

* Estimativa

Organizações Rurais \& Agroindustriais, Lavras, v. 18, n. 4, p. 289-303, 2016 
tornou possível a recomposição dos estoques mundiais de grão, conforme se observa na tabela acima, e teve impacto na flutuação dos preços mundiais. Após nova queda dos estoques em 2011, houve nova recuperação dos estoques em 2012 com perspectiva de recuperação também em 2013 como pode ser observado na Tabela 2.

Entretanto, apesar da safra mundial de 2010/11 ter alcançado um recorde, produzindo 263,4 milhões de toneladas, sobretudo aquela originada da China, foi possível garantir a recuperação das cotações do grão durante o segundo semestre de 2010. Entre agosto de 2010 e na metade de 2011, os preços nominais da soja tiveram uma evolução de 9,35\% (HIRAKURI, 2010).

Com a crescente demanda do produto pelo mercado Chinês, atualmente é pouco provável um aumento significativo dos estoques de passagem o que deve garantir certa estabilidade dos preços ou até mesmo um viés de aumento nos próximos anos.

\section{EFEITOS DA LEI KANDIR E DA CHINA PARA AS EXPORTAÇÕES DO COMPLEXO DE SOJA NO BRASIL}

Boa parte do excelente desempenho do agronegócio brasileiro no ano de 2003, quando se apresentou um crescimento de $6,54 \%$ em relação a 2002 , deveu-se ao segmento da soja, líder do ranking das exportações nesse $a^{3}{ }^{3}$. Os principais mercados de destino da soja brasileira naquele período, em ordem decrescente de importância, foram: China, Países Baixos, Alemanha, Espanha, Itália, Japão e França, sendo o Brasil também o principal vendedor de soja para o mercado europeu (GARCIA e ZAPAROLLI, 2006).

3'nforme Departamento Econômico, N. 71FAESP-SP:2004.
Ainda no que concerne aos saldos comerciais do complexo da soja, estes têm sido cada vez maiores, sendo que entre 2002 e 2013 houve um aumento expressivo do saldo comercial, passando de cerca de U\$ 5 bilhões para aproximadamente U\$ 30 bilhões, o que representa um aumento de cerca de $600 \%$ (Figura 1).

É importante destacar que o interesse da China, cujo consumo iniciou-se em 1996, e do Japão pela soja brasileira vem crescendo e que não são avessos a organismos geneticamente modificados (ogm’s), pois compram também as sojas transgênicas dos EUA. Dessa forma, a liberação do plantio de soja transgênica no Brasil abriu a possibilidade de expansão desta variedade no campo brasileiro e, consequentemente, de enfrentar a concorrência dos EUA e da Argentina, no segmento internacional da soja transgênica (GARCIA e ZAPAROLLI, 2006).

Entretanto, por mais que se tenha tido este esplendoroso aumento do saldo comercial na comercialização do complexo de soja, há diversos estudos que propõem que este aumento tem sido puxado principalmente pela exportação de grãos in natura sem qualquer tipo de processamento e que um dos principais motivos para isso foi a promulgação da Lei Kandir em 1996 e o advento da China, consumidor principalmente de grãos e que utiliza de escalada tarifária à medida que o Brasil impõe agregação de valor ao produto.

A Lei Kandir, que desonerou as exportações de produtos básicos e semielaborados de ICMS, estimulando a exportação de soja em grão em detrimento dos subprodutos farelo e óleo, que possuem maior valor adicionado.

A partir da Tabela 3, a seguir, pode ser verificado o impacto de cada um destes fatores sobre a pauta exportadora brasileira de grãos de soja e de óleo e farelo, sendo os últimos dois, produtos já com algum grau de manufatura e agregação de valor.

TABELA 2 - Estoque final soja mundo (milhões de toneladas)

\begin{tabular}{|c|c|c|c|c|c|}
\hline País/Safra & $2009 / 10$ & $2010 / 11$ & 2011/12 & $2012 / 13$ & $2013 / 14^{*}$ \\
\hline Argentina & 22.28 & 22.87 & 18.10 & 25.95 & 27.07 \\
\hline Brasil & 17.48 & 23.64 & 12.92 & 17.76 & 21.21 \\
\hline China & 13.26 & 14.56 & 15.92 & 11.59 & 13.86 \\
\hline Estados Unidos & 4.11 & 5.85 & 4.61 & 3.41 & 5.99 \\
\hline Índia & 1.57 & 0.51 & 0.32 & 0.39 & 0.87 \\
\hline Outros & 3.52 & 4.30 & 2.99 & 3.12 & 3.27 \\
\hline Total & 62.22 & 71.73 & 54.86 & 62.22 & 72.27 \\
\hline
\end{tabular}

Fonte: Usda - Agosto de 2013, adaptado CONAB - Conjunturas Especiais - 2013

* Estimativa 


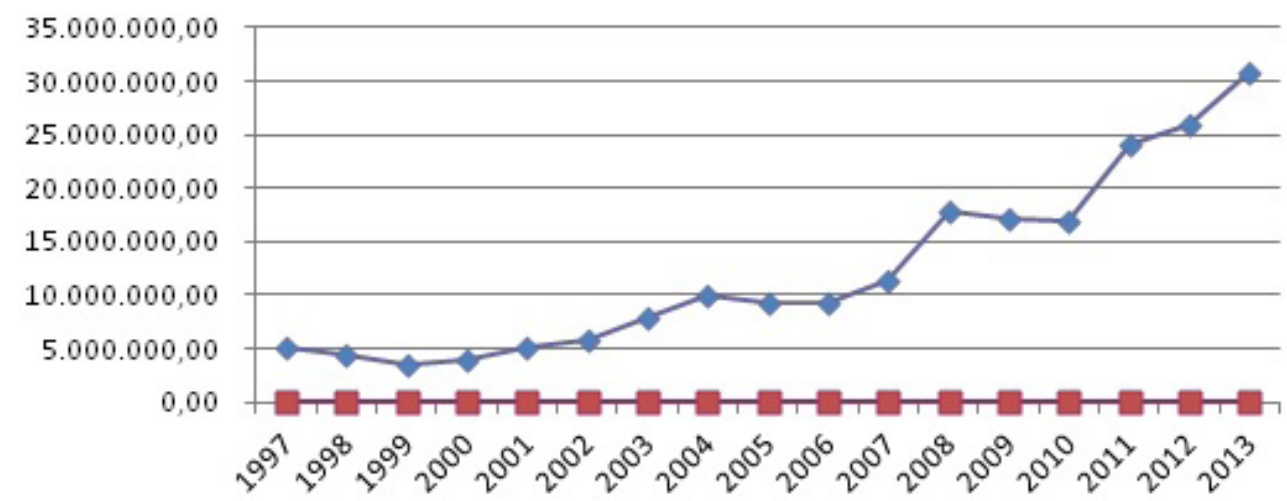

FIGURA 1 - Complexo da soja - Saldo comercial do Brasil em 1000 U\$

Fonte: Elaboração própria a partir de dados do Agrostat

Primeiramente pode ser analisado o impacto da Lei Kandir sobre as exportações de Soja in natura e sobre outros produtos mais elaborados como óleo e farelo. Para isso, a tabela acima foi dividida em dois períodos. O primeiro período refere-se ao período anterior a promulgação da Lei Kandir. Observe que nesse período, a média de participação do Brasil na exportação de grãos no mundo era de $11 \%$, enquanto que no segundo período o Brasil detinha $26 \%$ do mercado mundial, isso pelo menos à princípio, indica que a Lei Kandir pode ter estimulado a exportação do produto in natura em detrimento da exportação de óleo e farelo, que possuem maior valor agregado.

Analisando agora a participação do óleo e farelo de soja, enquanto que na média do período até 1996 o Brasil detinha 22\% do mercado mundial de óleo e $31 \%$ do mercado de farelo de soja, no período posterior a 1996 o Brasil deteve, em média, 21\% do mercado de óleo e $25 \%$ do mercado de farelo.

Sendo assim, no período, houve redução na participação do mercado mundial de ambos os produtos. Mais uma vez tal fato parece estar de certo modo associado à promulgação da Lei Kandir e às barreiras tarifárias e não tarifárias impostas pelos países importadores conforme pode se constatar também no trabalho de Rodrigues et al. (2011).

Agora considere o impacto da China na evolução da pauta de exportação da soja e derivados do Brasil. Observe que no período anterior à promulgação da Lei Kandir, que também coincide com uma época de baixo consumo da China de soja, praticamente nada das exportações brasileiras de soja in natura tinha como destino a China.

Fato totalmente contrário ao que se observa no segundo período, no qual. em média, 37\% do total exportado de soja em grãos pelo Brasil foram direcionados à China, chegando a ser um percentual de $70 \%$ do total exportado em 2011. Isto mostra claramente uma estratégia adotada por este parceiro comercial, que é importar produtos in natura para processamento e agregação de valor na economia doméstica.

Em relação ao óleo de soja, nos dois períodos observados, a participação da China no total exportado manteve-se praticamente o mesmo nos dois períodos de análise. A China já era um consumidor do óleo brasileiro e manteve o mesmo padrão de importação.

O que chama a atenção na relação sino-brasileira é o comércio de farelo de soja. A partir de 1996, a China ${ }^{4}$ aumentou o seu consumo de farelo no mercado mundial. Entretanto, esse aumento de consumo não se compara ao que foi observado na importação de grãos. Além disso, parte desse aumento foi ocasionado, provavelmente por fatores esporádicos, pois na realidade a China é exportadora de farelo. Desde o início da série, a China é o sétimo país que mais exportou farelo.

Por fim, o que se pode observar é que após a implantação da Lei Kandir houve um aumento significativo da quantidade de soja em grãos em detrimento de outros subprodutos como óleo e farelo. Entretanto, o setor que mais perdeu mercado no mundo foi o de exportação de farelo de soja, cuja participação brasileira caiu de uma média de $31 \%$ do total exportado para uma média de $25 \%$. Este setor parece ter perdido parte da competitividade após a promulgação da Lei Kandir. O setor de óleo manteve sua participação praticamente a mesma durante os dois períodos.

${ }^{4}$ Informe Departamento Econômico, N. 71FAESP-SP:2004. 
TABELA 3 - Participação do Brasil no comércio mundial de soja e peso da China como país de destino

\begin{tabular}{|c|c|c|c|c|c|c|}
\hline \multirow{2}{*}{$\begin{array}{c}\text { Produto } \\
\text { Ano }\end{array}$} & \multicolumn{2}{|c|}{ Soja em Grãos } & \multicolumn{2}{|c|}{ Óleo de Soja } & \multicolumn{2}{|c|}{ Farelo de Soja } \\
\hline & $\begin{array}{l}\text { \% Exportado } \\
\text { para a China }\end{array}$ & $\begin{array}{c}\text { \% Brasil/ } \\
\text { Mundo }\end{array}$ & $\begin{array}{l}\text { \% Exportado } \\
\text { para a China }\end{array}$ & $\begin{array}{c}\text { \% Brasil/ } \\
\text { Mundo }\end{array}$ & $\begin{array}{l}\text { \% Exportado } \\
\text { para a China }\end{array}$ & $\begin{array}{c}\text { \% Brasil/ } \\
\text { Mundo }\end{array}$ \\
\hline 1986 & $0 \%$ & $3 \%$ & $37 \%$ & $11 \%$ & $0 \%$ & $27 \%$ \\
\hline 1987 & $0 \%$ & $9 \%$ & $15 \%$ & $27 \%$ & $0 \%$ & $34 \%$ \\
\hline 1988 & $0 \%$ & $10 \%$ & $14 \%$ & $19 \%$ & $0 \%$ & $29 \%$ \\
\hline 1989 & $0 \%$ & $17 \%$ & $33 \%$ & $26 \%$ & $0 \%$ & $36 \%$ \\
\hline 1990 & $0 \%$ & $15 \%$ & $32 \%$ & $23 \%$ & $1 \%$ & $30 \%$ \\
\hline 1991 & $0 \%$ & $7 \%$ & $19 \%$ & $14 \%$ & $0 \%$ & $24 \%$ \\
\hline 1992 & $0 \%$ & $13 \%$ & $16 \%$ & $17 \%$ & $2 \%$ & $29 \%$ \\
\hline 1993 & $0 \%$ & $14 \%$ & $4 \%$ & $18 \%$ & $0 \%$ & $32 \%$ \\
\hline 1994 & $0 \%$ & $17 \%$ & $50 \%$ & $29 \%$ & $0 \%$ & $33 \%$ \\
\hline 1995 & $0 \%$ & $11 \%$ & $54 \%$ & $29 \%$ & $0 \%$ & $34 \%$ \\
\hline 1996 & $0 \%$ & $10 \%$ & $61 \%$ & $28 \%$ & $9 \%$ & $36 \%$ \\
\hline Média até 1996 & $0 \%$ & $11 \%$ & $31 \%$ & $22 \%$ & $1 \%$ & $31 \%$ \\
\hline 1997 & $6 \%$ & $21 \%$ & $50 \%$ & $19 \%$ & $10 \%$ & $30 \%$ \\
\hline 1998 & $15 \%$ & $24 \%$ & $17 \%$ & $19 \%$ & $12 \%$ & $27 \%$ \\
\hline 1999 & $7 \%$ & $22 \%$ & $10 \%$ & $21 \%$ & $1 \%$ & $27 \%$ \\
\hline 2000 & $16 \%$ & $24 \%$ & $11 \%$ & $16 \%$ & $1 \%$ & $25 \%$ \\
\hline 2001 & $22 \%$ & $27 \%$ & $8 \%$ & $20 \%$ & $0 \%$ & $26 \%$ \\
\hline 2002 & $27 \%$ & $29 \%$ & $20 \%$ & $22 \%$ & $0 \%$ & $27 \%$ \\
\hline 2003 & $33 \%$ & $30 \%$ & $26 \%$ & $25 \%$ & $0 \%$ & $26 \%$ \\
\hline 2004 & $34 \%$ & $33 \%$ & $37 \%$ & $26 \%$ & $0 \%$ & $29 \%$ \\
\hline 2005 & $34 \%$ & $34 \%$ & $15 \%$ & $26 \%$ & $0 \%$ & $25 \%$ \\
\hline 2006 & $45 \%$ & $36 \%$ & $11 \%$ & $21 \%$ & $0 \%$ & $21 \%$ \\
\hline 2007 & $43 \%$ & $32 \%$ & $19 \%$ & $19 \%$ & $0 \%$ & $20 \%$ \\
\hline 2008 & $49 \%$ & $31 \%$ & $31 \%$ & $20 \%$ & $0 \%$ & $20 \%$ \\
\hline 2009 & $58 \%$ & $35 \%$ & $34 \%$ & $16 \%$ & $0 \%$ & $21 \%$ \\
\hline 2010 & $64 \%$ & $29 \%$ & $61 \%$ & $15 \%$ & $0 \%$ & $21 \%$ \\
\hline 2011 & $70 \%$ & $39 \%$ & $38 \%$ & $18 \%$ & $0 \%$ & $22 \%$ \\
\hline Média pós 1996 & $37 \%$ & $26 \%$ & $28 \%$ & $21 \%$ & $1 \%$ & $26 \%$ \\
\hline
\end{tabular}

Fonte: Elaboração própria a partir de dados da FAO

Obs.: A tabela completa por tipo de produto pode ser visualizada em anexo

Esse resultado também foi encontrado por outros pesquisadores como Lopes et al. (2013), Schlesinger (2008), e pode ser observado também no trabalho de CALDARELLI et al. (2009), no qual o autor mostrou que a Lei Kandir (1996) interrompeu um ciclo de aceleração do cultivo de soja, transferindo a margem da agroindústria para o setor produtor primário e aos exportadores, o que levou ao desestímulo da produção de derivados com algum grau de processamento no Brasil.
Outro fato de destaque, é que o aumento no Brasil de participação no total exportado de grãos no mercado mundial ocorreu principalmente por sua relação comercial com a China, que tem clara preferência por importação de grãos, que possui pouco valor agregado, para posterior beneficiamento na economia doméstica. Neste cenário, se antes de 1996 a China já não importava o farelo de soja em grandes somas do Brasil, após esse período também não houve estímulo a tal importação. 
Por fim, cabe esclarecer aqui que não foi realizado o avanço do Brasil no comércio mundial de carnes, que é um grande consumidor de farelo de soja, principalmente para fabricação de ração. Talvez seja interessante fazer uma análise também deste setor para que se tenha mais um argumento de análise.

\section{CONSIDERAÇÕES FINAIS}

O presente trabalho apresentou como objetivo examinar se houve um redirecionamento da pauta exportadora do complexo de soja, com acentuação da exportação de produto com menor valor agregado, soja em grãos in natura, em detrimento da exportação de produtos com maior valor agregado como farelo e óleo e, se houve, qual a ligação desse processo com a promulgação da Lei Kandir e com o advento da China como maior importador mundial do produto.

$\mathrm{Da}$ análise dos dados referentes ao período foi possível observar que, de fato, após 1996, houve um aumento da exportação de soja em grãos em detrimento da exportação de óleo e farelo. Enquanto que a participação do Brasil no comércio mundial de soja em grãos no primeiro período foi de $11 \%$, no segundo período de análise o Brasil detinha $26 \%$ do mercado mundial de soja em grãos. Caso destoante do comércio de farelo, que no primeiro período a participação brasileira foi de $31 \%$ contra $25 \%$ no segundo período.

Os dados indicam que essa queda da participação brasileira do mercado de farelo de soja está tanto associada à promulgação da Lei Kandir em 1996, quanto em decorrência da parceria comercial com a China, que pratica escalada tarifária com clara preferência em importar produtos de menor valor agregado, no caso soja em grãos para posterior beneficiamento.

Entretanto, apesar de entender que a Lei Kandir pode ter sido uma das fontes do aumento da participação da exportação de soja em grãos em detrimento de outros produtos mais bem elaborados, não foi possível, nesse trabalho, mensurar o impacto que o fim da isenção para exportação da soja seria benéfico ou não para o país.

Apesar dessa impossibilidade de mensuração, é plausível que considerando que a China dificilmente conseguirá suprir no mercado internacional a sua demanda sem a soja brasileira e que em 2011 o Brasil deteve cerca de $40 \%$ do mercado mundial de soja em grãos o que lhe garante certo poder de mercado, parece razoável propor um debate sobre essa questão.

Esse debate é importante, pois a expansão das exportações da soja in natura em detrimento de produtos manufaturados de maior valor agregado é prejudicial para o desenvolvimento da economia brasileira tendo em vista que a agregação de valor de produtos básicos permite a geração de maior número de empregos, impulsiona investimentos em pesquisa e desenvolvimento e propicia um incremento de valor aos produtos que são exportados.

Como razão adicional para a construção desse debate, tem-se o fato de os dados mostrarem que, muito embora ainda haja certa diversificação da pauta exportadora, num futuro não distante, o aprofundamento de desequilíbrios tributários pode fazer com que o país se torne um mero exportador de soja em grãos em detrimento de produtos mais bem elaborados e com um valor agregado mais alto.

A preocupação com o aprofundamento da dependência do setor primário também é relevante, pois são os setores de manufaturados que costumam gerar maiores efeitos de encadeamento para frente e para trás na cadeia produtiva, que possuem maior elasticidade renda das importações, o que contribui para aumento das exportações com o aumento da renda global e que, em função da geração de maior valor agregado propiciam a geração de empregos com salários mais altos, o que também é importante para o desenvolvimento econômico do país.

Ressalta-se também que além de gerar menor riqueza, a exportação de grãos poderá exigir cada vez mais investimentos em infraestrutura, caso contrário, a situação caótica dos portos e estradas brasileiras poderá se agravar ainda mais.

Por fim, independente do debate proposto acima e considerando que, em 2011, $70 \%$ da soja brasileira foi exportada para a China, é preciso que haja investimentos em pesquisa e desenvolvimento de novos produtos da soja e não apenas pesquisas que visem ao aumento da produtividade no campo. Com isso, poderia haver maior agregação de valor, construção e ampliação de importantes efeitos de ligação com a economia local, e também diminuição da dependência do setor externo, em especial, da dependência da China como principal compradora.

\section{REFERÊNCIAS}

ABIOVE, Associação brasileira de indústrias de óleos vegetais. Disponível em: <http://www.abiove.com.br>. Acesso em: jan. 2014.

AGNOL, A., D.; LAZAROTTO, J., J.; HIRAKURI, H., M. Desenvolvimento, Mercado e Rentabilidade da Soja Brasileira. Circular Técnica 74 - EMBRAPA, Londrina-PR, 2010. 
BENETTI, Maria Domingues. Boom exportador: ruptura ou continuidade do padrão de comércio brasileiro? Indicadores Econômicos FEE, v. 34, n. 1, p. 75-88, 2006.

BRESSER-PEREIRA, LUIZ CARLOS - "DOENÇA HOLANDESA E SUA NEUTRALIZAÇÃO: UMA ABORDAGEM RICARDIANA", IN DOENÇA HOLANDESA E A INDÚSTRIA, EDITORA DA FUNDAÇÃO GETÚLIO VARGAS, 2008.

BOIFÁCIO, R., D., T; SALES, V., G.; LIMA, E., L:, RODRIGUES, A., M. Desempenho dos pacotes agrícolas no Brasil: uma analise da dinâmica de exportação da soja 1995-2013. VIII SOBER Nordeste, Parnaíba-PI, 2013.

BRUM, A. L.; HECK, C. R.; LEMES, C. L.; MÜLLER, P. K.: A economia mundial da soja: impactos na cadeia produtiva da oleaginosa no Rio Grande do Sul 1970-2000. Anais dos Congressos. XLIII Congresso da Sober em Ribeirão Preto. São Paulo, 2005.

CALDARELLI, C. E., DA CAMARA, M. R. G., \& SEREIA, V. J. Exportação e Competitividade do Complexo Soja Brasileiro e Paranaense de 1990 A 2007. Anais dos Congressos. $47^{\circ}$ Congresso da Sober em Porto Alegre. Porto Alegre, 2009. Disponível em: http://www.sober.org. br/palestra/13/30.pdf

CARVALHO, Maria Auxiliadora de; SILVA, César Roberto Leite da. Mudanças na pauta das exportações agrícolas brasileiras. Revista de Economia e Sociologia Rural, v. 46, n. 1, p. 53-73, 2008.

CARVAlho, D. F.; CARVAlho, A. C. Desindustrialização e reprimarizaçãoda economia brasileira contemporânea num contexto de crise financeiraglobal: conceitos e evidências. Revista Economia Ensaios, Uberlândia (MG),26 (1), p. 35-64, Jul./Dez. 2011.

CARVALHO, Lauda; KUPFER, David. Diversificação ou especialização: uma análise do processo de mudança estrutural da indústria brasileira. Revista de Economia Política, vol. 31, no 4 (124), pp. 618-637, outubrodezembro/2011.

CONAB, Companhia Nacional de Abastecimento. Conjunturas Prospecção - Soja. Disponível em: http://conab.gov.br/OlalaCMS/uploads/ arquivos/13_09_13_10_33_09_7_soja.pdf
DA COSTA, Kaio Glauber Vital; DE OLIVEIRA GONÇALVES, Flávio. Desindustrialização e especialização tecnológica: uma análise empírica entre 1989-2010. 39 ${ }^{\circ}$ Encontro de Economia Brasileira ANPEC, 2011.

DO NASCIMENTO, Carlos Alves; CARDOZO, Soraia. "Reprimarização ou dependência estrutural de commodities? O debate em seu devido lugar." II encontro da Associação Keynesiana Brasileira (2009).

IMBS, J.; WACZIARG, R. "Stages of diversification". American Economic Review, 93(1): 63- 86. 2003.

FAO, FoodAgricultureOrganization. Banco de dados. Disponível em: <http://fao.com>. Acesso em: jan. 2014.

GARCIA, M. de F.; ZAPAROLLI, M., J., S. Perspectivas para a soja Brasileira no Comércio Mundial: um ensaio sobre o conflito da soja transgênica versus soja convencional a partir da aplicação de um jogo com estratégias mistas. Encontro Nacional de Economia (ANPEC), Salvador-BA, 2006.

HELPER, Susan; KRUEGER, Timothy; WIAL, Howard. Why Does Manufacturing Matter? Which Manufacturing Matters?. MetropolitanPolicyProgrampaper, p. 1-53, 2012.

HIRAKURI, H., M. Avaliação do Desempenho Econômicofinanceiro da Produção de Soja no Estado do Paraná, para a Safra de 2011/2012. Circular Técnica 88 - EMBRAPA, Londrina-PR, 2010.

Lopes, M. M., da Silva, R. A., Coronel, D. A., Vieira, K. M., \& de Freitas, C. A. (2013). Análise da competitividade e das exportações agrícolas brasileiras para a China: uma análise do complexo soja e fumo. Revista Uniabeu, 6(13), 189-208.

NASCIMENTO, Carlos Alves; CARDOZO, Soraia Aparecida; NASCIMENTO, Katiucy

Lemes. O sentido da reprimarização da pauta exportadora: uma interpretação à luz de Celso Furtado, Caio Prado Jr. e Francisco de Oliveira. In: 46th Congress, July 20-23, 2008, Rio Branco, Acre, Brasil. Sociedade Brasileira de Economia, Administracao e Sociologia Rural (SOBER), 2008. 
NASSIF, André. "Há evidências de desindustrialização no Brasil?." Revista de economia política 28.1 (2008): 72-96.

OREIRO, José Luis; FEIJÓ, Carmem A.'Desindustrialização: conceituação, causas, efeitos e o caso brasileiro."Revista de economia política" 30.2 (2010): 219-232.

PAULA, S. R.de; FAVERET FILHO, P. Panorama do Complexo da Soja. Rio de Janeiro : Ed. BNDES, setembro de 1998, volume 8. pg. 119-152.

RODRIGUES, F. R. et al. Escalada tarifária e exportações brasileiras daagroindústria do café e da soja. Rev. Econ. Sociol. Rural, Brasília, v. 49, n.2, 2011 .

RODRIK, D.The Past, Present, and Future of Economic Growth.Global Citizen Foundation.WORKING PAPER 1, JUNE, 2013.
ROESSING, C. A.; LAZZAROTTO, J. J. Criação de Empregos pelo Complexo Agroindustrial da Soja. Embrapa Documentos 233, Londrina-PR, 2004.

SCHLESINGER, Sergio. Soja: o grão que segue crescendo. Grupo de Trabalho sobre Desenvolvimento e Meio Ambiente nas Américas, 2008.

SILVA, José Aldenir. Desindustrialização e doença holandesa: o caso brasileiro. Indic. Econ. FEE, Porto Alegre, v. 41, n. 3, p. 67-82, 2014.

SONAGLIO, Cláudia Maria et al. Evidências de desindustrialização no Brasil: uma análise com dados em painel. Economia Aplicada, v. 14, n. 4, p. 347-372, 2010.

VERÍSSIMO, Michele Polline; XAVIER, Clésio Lourenço. Taxa de câmbio, exportações e crescimento: uma investigação sobre a hipótese de doença holandesa no Brasil. Revista de Economia Politica, vol. 33, n. 1 (130), pp. 82-101, janeiro-marco/2013.

Organizações Rurais \& Agroindustriais, Lavras, v. 18, n. 4, p. 289-303, 2016 
ANEXO 1 - Participação do Brasil no mercado mundial - Soja em grãos

\begin{tabular}{|c|c|c|c|c|c|}
\hline Ano & $\begin{array}{c}\text { Brasil - Total } \\
\text { Exportado }\end{array}$ & $\begin{array}{c}\text { Br - Exportação para } \\
\text { a China }\end{array}$ & $\begin{array}{c}\text { \% Exportado para a } \\
\text { China }\end{array}$ & $\begin{array}{c}\text { Exportação Mundo } \\
\text { - Total }\end{array}$ & $\%$ do Brasil/ Mundo \\
\hline 1986 & $617,958.00$ & 0.00 & $0 \%$ & $22,840,628.00$ & $3 \%$ \\
\hline 1987 & $2,683,573.00$ & $3,780.00$ & $0 \%$ & $29,954,574.00$ & $9 \%$ \\
\hline 1988 & $2,504,011.00$ & 0.00 & $0 \%$ & $26,171,257.00$ & $10 \%$ \\
\hline 1989 & $4,235,711.00$ & $14,000.00$ & $0 \%$ & $25,191,656.00$ & $17 \%$ \\
\hline 1990 & $3,903,437.00$ & 0.00 & $0 \%$ & $26,314,945.00$ & $15 \%$ \\
\hline 1991 & $2,020,437.00$ & 0.00 & $0 \%$ & $28,501,777.00$ & $7 \%$ \\
\hline 1992 & $3,725,982.00$ & 0.00 & $0 \%$ & $29,577,754.00$ & $13 \%$ \\
\hline 1993 & $4,184,705.00$ & 0.00 & $0 \%$ & $29,389,406.00$ & $14 \%$ \\
\hline 1994 & $5,397,590.00$ & $6,200.00$ & $0 \%$ & $31,660,362.00$ & $17 \%$ \\
\hline 1995 & $3,492,525.00$ & 0.00 & $0 \%$ & $32,528,183.00$ & $11 \%$ \\
\hline 1996 & $3,646,935.00$ & $14,960.00$ & $0 \%$ & $35,188,188.00$ & $10 \%$ \\
\hline 1997 & $8,339,591.00$ & $492,977.00$ & $6 \%$ & $39,737,148.00$ & $21 \%$ \\
\hline 1998 & $9,274,752.00$ & $1,367,549.00$ & $15 \%$ & $38,251,599.00$ & $24 \%$ \\
\hline 1999 & $8,917,210.00$ & $632,671.00$ & $7 \%$ & $40,613,284.00$ & $22 \%$ \\
\hline 2000 & $11,517,266.00$ & $1,897,975.00$ & $16 \%$ & $47,714,589.00$ & $24 \%$ \\
\hline 2001 & $15,675,543.00$ & $3,451,943.00$ & $22 \%$ & $57,385,589.00$ & $27 \%$ \\
\hline 2002 & $15,970,004.00$ & $4,334,399.00$ & $27 \%$ & $55,108,056.00$ & $29 \%$ \\
\hline 2003 & $19,890,470.00$ & $6,657,634.00$ & $33 \%$ & $65,506,371.00$ & $30 \%$ \\
\hline 2004 & $19,247,690.00$ & $6,519,009.00$ & $34 \%$ & $58,244,169.00$ & $33 \%$ \\
\hline 2005 & $22,435,075.00$ & $7,667,386.00$ & $34 \%$ & $66,059,543.00$ & $34 \%$ \\
\hline 2006 & $24,957,976.00$ & $11,295,900.00$ & $45 \%$ & $68,551,520.00$ & $36 \%$ \\
\hline 2007 & $23,733,774.00$ & $10,287,987.00$ & $43 \%$ & $75,217,564.00$ & $32 \%$ \\
\hline 2008 & $24,499,490.00$ & $12,011,563.00$ & $49 \%$ & $79,859,852.00$ & $31 \%$ \\
\hline 2009 & $28,562,711.00$ & $16,507,849.00$ & $58 \%$ & $82,094,223.00$ & $35 \%$ \\
\hline 2010 & $25,860,785.00$ & $16,486,729.00$ & $64 \%$ & $87,721,528.00$ & $29 \%$ \\
\hline 2011 & $32,985,562.00$ & $23,071,797.00$ & $70 \%$ & $84,529,392.00$ & $39 \%$ \\
\hline Total Geral & $328,280,763.00$ & $122,722,308.00$ & $37 \%$ & $1,263,913,157.00$ & $26 \%$ \\
\hline
\end{tabular}

Fonte: Elaboração própria a partir de dados da FAO - Matriz detalhada do comércio mundial. 
ANEXO II - Participação do Brasil no Mercado Mundial - Óleo de Soja

\begin{tabular}{|c|c|c|c|c|c|}
\hline Ano & $\begin{array}{l}\text { Brasil - Total } \\
\text { Exportado }\end{array}$ & $\begin{array}{c}\text { Br - Exportação para } \\
\text { a China }\end{array}$ & $\begin{array}{c}\text { \% Exportado para a } \\
\text { China }\end{array}$ & $\begin{array}{c}\text { Exportação Mundo } \\
\text { - Total }\end{array}$ & $\%$ do Brasil/ Mundo \\
\hline 1986 & $251,200.00$ & $93,842.00$ & $37 \%$ & $2,287,536.00$ & $11 \%$ \\
\hline 1987 & $988,583.00$ & $148,845.00$ & $15 \%$ & $3,672,178.00$ & $27 \%$ \\
\hline 1988 & $666,956.00$ & $96,350.00$ & $14 \%$ & $3,566,506.00$ & $19 \%$ \\
\hline 1989 & $890,627.00$ & $292,785.00$ & $33 \%$ & $3,457,493.00$ & $26 \%$ \\
\hline 1990 & $794,324.00$ & $251,125.00$ & $32 \%$ & $3,458,274.00$ & $23 \%$ \\
\hline 1991 & $512,218.00$ & $98,395.00$ & $19 \%$ & $3,614,658.00$ & $14 \%$ \\
\hline 1992 & $718,676.00$ & $118,091.00$ & $16 \%$ & $4,257,110.00$ & $17 \%$ \\
\hline 1993 & $746,043.00$ & $27,250.00$ & $4 \%$ & $4,061,877.00$ & $18 \%$ \\
\hline 1994 & $1,533,302.00$ & $764,988.00$ & $50 \%$ & $5,259,425.00$ & $29 \%$ \\
\hline 1995 & $1,763,959.00$ & $950,873.00$ & $54 \%$ & $6,070,065.00$ & $29 \%$ \\
\hline 1996 & $1,332,256.00$ & $817,901.00$ & $61 \%$ & $4,768,735.00$ & $28 \%$ \\
\hline 1997 & $1,125,893.00$ & $562,630.00$ & $50 \%$ & $6,058,875.00$ & $19 \%$ \\
\hline 1998 & $1,359,890.00$ & $230,104.00$ & $17 \%$ & $7,322,224.00$ & $19 \%$ \\
\hline 1999 & $1,551,812.00$ & $156,487.00$ & $10 \%$ & $7,565,598.00$ & $21 \%$ \\
\hline 2000 & $1,072,994.00$ & $121,899.00$ & $11 \%$ & $6,910,184.00$ & $16 \%$ \\
\hline 2001 & $1,651,528.00$ & $135,698.00$ & $8 \%$ & $8,320,979.00$ & $20 \%$ \\
\hline 2002 & $1,934,385.00$ & $386,208.00$ & $20 \%$ & $8,970,164.00$ & $22 \%$ \\
\hline 2003 & $2,485,992.00$ & $646,193.00$ & $26 \%$ & $9,981,244.00$ & $25 \%$ \\
\hline 2004 & $2,517,241.00$ & $935,186.00$ & $37 \%$ & $9,554,520.00$ & $26 \%$ \\
\hline 2005 & $2,697,053.00$ & $394,143.00$ & $15 \%$ & $10,525,625.00$ & $26 \%$ \\
\hline 2006 & $2,419,379.00$ & $255,136.00$ & $11 \%$ & $11,443,366.00$ & $21 \%$ \\
\hline 2007 & $2,342,543.00$ & $446,754.00$ & $19 \%$ & $12,436,989.00$ & $19 \%$ \\
\hline 2008 & $2,315,837.00$ & $716,556.00$ & $31 \%$ & $11,408,754.00$ & $20 \%$ \\
\hline 2009 & $1,593,648.00$ & $546,814.00$ & $34 \%$ & $9,855,775.00$ & $16 \%$ \\
\hline 2010 & $1,559,778.00$ & $948,465.00$ & $61 \%$ & $10,517,929.00$ & $15 \%$ \\
\hline 2011 & $1,741,411.00$ & $663,331.00$ & $38 \%$ & $9,855,391.00$ & $18 \%$ \\
\hline Total Geral & $38,567,528.00$ & $10,806,049.00$ & $28 \%$ & $185,201,474.00$ & $21 \%$ \\
\hline
\end{tabular}

Fonte: Elaboração própria a partir de dados da FAO - Matriz detalhada do comércio mundial 
ANEXO III - Participação do Brasil no Mercado Mundial - Farelo de Soja

\begin{tabular}{|c|c|c|c|c|c|}
\hline Ano & $\begin{array}{c}\text { Brasil - Total } \\
\text { Exportado }\end{array}$ & $\begin{array}{c}\text { Br - Exportação para } \\
\text { a China }\end{array}$ & $\begin{array}{c}\text { \% Exportado para a } \\
\text { China }\end{array}$ & $\begin{array}{c}\text { Exportação Mundo } \\
\text { - Total }\end{array}$ & $\%$ do Brasil/ Mundo \\
\hline 1986 & $3,470,514.00$ & 0.00 & $0 \%$ & $13,072,922.00$ & $27 \%$ \\
\hline 1987 & $7,061,508.00$ & 0.00 & $0 \%$ & $20,927,425.00$ & $34 \%$ \\
\hline 1988 & $7,739,612.00$ & 1.00 & $0 \%$ & $27,092,074.00$ & $29 \%$ \\
\hline 1989 & $9,380,328.00$ & $30,438.00$ & $0 \%$ & $26,148,985.00$ & $36 \%$ \\
\hline 1990 & $8,204,037.00$ & $68,049.00$ & $1 \%$ & $26,905,032.00$ & $30 \%$ \\
\hline 1991 & $7,488,583.00$ & 0.00 & $0 \%$ & $30,603,379.00$ & $24 \%$ \\
\hline 1992 & $8,548,654.00$ & $131,397.00$ & $2 \%$ & $29,917,118.00$ & $29 \%$ \\
\hline 1993 & $9,414,380.00$ & $31,261.00$ & $0 \%$ & $29,411,595.00$ & $32 \%$ \\
\hline 1994 & $10,643,845.00$ & $50,135.00$ & $0 \%$ & $31,797,252.00$ & $33 \%$ \\
\hline 1995 & $11,596,514.00$ & $45,315.00$ & $0 \%$ & $33,644,907.00$ & $34 \%$ \\
\hline 1996 & $11,261,700.00$ & $966,577.00$ & $9 \%$ & $31,168,792.00$ & $36 \%$ \\
\hline 1997 & $10,013,359.00$ & $979,927.00$ & $10 \%$ & $33,276,622.00$ & $30 \%$ \\
\hline 1998 & $10,446,984.00$ & $1,258,313.00$ & $12 \%$ & $38,926,854.00$ & $27 \%$ \\
\hline 1999 & $10,430,879.00$ & $92,473.00$ & $1 \%$ & $38,894,127.00$ & $27 \%$ \\
\hline 2000 & $9,389,188.00$ & $67,721.00$ & $1 \%$ & $37,195,479.00$ & $25 \%$ \\
\hline 2001 & $11,270,729.00$ & 313.00 & $0 \%$ & $43,555,096.00$ & $26 \%$ \\
\hline 2002 & $12,517,156.00$ & 197.00 & $0 \%$ & $46,957,673.00$ & $27 \%$ \\
\hline 2003 & $13,602,160.00$ & 214.00 & $0 \%$ & $51,416,056.00$ & $26 \%$ \\
\hline 2004 & $14,485,625.00$ & 242.00 & $0 \%$ & $50,199,873.00$ & $29 \%$ \\
\hline 2005 & $14,421,682.00$ & $5,124.00$ & $0 \%$ & $57,126,474.00$ & $25 \%$ \\
\hline 2006 & $12,332,350.00$ & $15,962.00$ & $0 \%$ & $58,766,043.00$ & $21 \%$ \\
\hline 2007 & $12,474,188.00$ & 0.00 & $0 \%$ & $62,973,491.00$ & $20 \%$ \\
\hline 2008 & $12,287,896.00$ & 650.00 & $0 \%$ & $60,562,436.00$ & $20 \%$ \\
\hline 2009 & $12,252,991.00$ & $1,635.00$ & $0 \%$ & $59,033,972.00$ & $21 \%$ \\
\hline 2010 & $13,668,599.00$ & 0.00 & $0 \%$ & $65,308,683.00$ & $21 \%$ \\
\hline 2011 & $14,355,170.00$ & $20,755.00$ & $0 \%$ & $64,677,974.00$ & $22 \%$ \\
\hline Total Geral & $278,758,631.00$ & $3,766,699.00$ & $1 \%$ & $1,069,560,334.00$ & $26 \%$ \\
\hline
\end{tabular}

Fonte: Elaboração própria a partir de dados da FAO - Matriz detalhada do comércio mundial. 